Schiff, L. (1963) Diseases of the Liver, 2nd edn, p. 698. Lippin Co. H., Philadelphia.

SHERLOCK, S. (1971a) The liver in secondary (early) syphilis. New England Journal of Medicine, 284, 1437.

SHERLOCK, S. (1971b) Diseases of the Liver and Biliary System, 4th edn,. p. 620. Blackwell Scientific Publications, Oxford.

Stokes, W.C., Beerman, C.E. \& Ingraham, E. (1944) Modern
Clinical Syphilology, 3rd edn., p. 109. W. B. Saunders Co., Philadelphia.

Warthin, A.S. (1918) The new pathology of syphilis. American Journal of Syphilis and Neurology, 2, 425.

Wile, U.J. \& KARShNER, R.G. (1917) Icterus gravis syphilitics: its relation to acute yellow atrophy Journal of the American Medical Association, 68, 1311.

\title{
Watery diarrhoea and hypokalaemia associated with a phaeochromocytoma
}

\author{
C. A. LOEHRY \\ M.D., B.Chir., M.R.C.P.
}

\author{
J. G. C. KinghaM \\ M.B., B.S., M.R.C.P.
}

\author{
P. J. WHORWELL \\ B.Sc., M.B., B.S., M.R.C.P. \\ Department of Medicine, Royal Victoria Hospital, Bournemouth
}

\begin{abstract}
Summary
The syndrome of water diarrhoea, hypokalaemia and achlorhydria (WDHA) is well described in association with a non-beta islet cell tumour of the pancreas. The following case report is of a 28-year-old woman with a WDHA syndrome that was cured by the removal of a phaeochromocytoma.
\end{abstract}

\section{Introduction}

Since Zollinger and Ellison described their syndrome in 1955 there has been an increasing number of descriptions of gastrointestinal disorders associated with hormone-secreting tumours at various sites. In 1958 Verner and Morrison described a syndrome of watery diarrhoea with hypokalaemia in which non-beta islet cell tumours of the pancreas were present, and there have been many similar cases appearing in the literature since. Achlorhydria is usually, but not always, present. These cases have been designated with various names, the commonest being pancreatic cholera, WDHA syndrome and Verner-Morrison syndrome. A number of hormones have been cited as the causative agent for this syndrome, but there now seems to be evidence that some at least of these may be caused by gastric inhibitory polypeptide (GIP) (Brown and Dryburgh, 1971; Elias et al., 1972; Pedersen and Brown, 1972), or vasoactive intestinal polypeptide (VIP) (Bloom, Poiak and Pearce, 1973). The following hormones and their sites of origin have been incriminated in the production of diarrhoea: gastrin from the gastric antrum or the pancreatic islets (Gregory et al., 1967; Polak, Stagg and Pearce, 1972); 5-hydroxytrypt- amine, kinins and histamine from carcinoid tumours (Oates and Butler, 1967); catecholamines from neural crest tumours, prostaglandins from neural crest tumours and medullary carcinoma of thyroid (Rosenstein and Engelman, 1963; Sandler, Karim and Williams, 1968; Williams, Karim and Sandler, 1968); thyroxine in hyperthyroidism, and histamine in systemic mastocytosis (Denis, 1963). Recently Pearce (1969) has postulated the concept of a series of closely related polypeptide and amine producing cells derived from the neural crest; these he has called APUD cells (amine precursor uptake and decarboxylase). Included amongst these are the antral $G$ cells (gastrin), the small intestinal D, I, S and EG cells (GIP, VIP, secretin and enteroglucagon respectively), the pancreatic islet $B, A$, and $D$ cells (insulin, glucagon and gastrin respectively), the $C$ cells of the thyroid (calcitonin), the corticotrophic and melanotrophic cells of the anterior pituitary (ACTH and MSH respectively), the phaeochromocytes (catechol amines), and the enterochromaffin EC cells (histamine, 5-hydroxytryptamine).

\section{Case report}

A 28-year-old-woman presented in 1968 with a 1year history of watery diarrhoea unassociated with blood or mucus. Examination, sigmoidoscopy and barium enema were unremarkable, and a diagnosis of mild ulcerative colitis was made. She was treated with anti-diarrhoeals and a milk-free diet. Her symptoms continued and the addition of salazopyrin, $1 \mathrm{~g}$ q.d.s. and prednisolone, $15 \mathrm{mg}$ daily produced little improvement. Shortly after this she complained of paroxysmal headaches with preceding palpitations 
and her general practitioner noticed marked fluctuations in her blood pressure (140/95 to $200 / 140 \mathrm{mmHg}$ ). A diagnosis of phaeochromocytoma was considered.

\section{Investigations}

Potassium $3.3 \mathrm{mEq} / 1$, other electrolytes normal; urea $32 \mathrm{mg} \%$; liver function tests and serum calcium normal; full blood picture normal; 5-hydroxyindolacetic acid excretion normal; synacthen test and PBI normal; rectal biopsy showed prominent lymphoid follicles, but was otherwise normal; a screening VMA test was weakly positive.

\section{Progress}

Unfortunately the patient was then lost to followup, until she returned 2 years later with unabated diarrhoea, abdominal pain, weight loss, anorexia and muscular weakness. Examination revealed a distended abdomen and a raised blood pressure of $140 / 95 \mathrm{mmHg}$. At this time an endocrine cause for her condition was suspected.

\section{Investigations}

Potassium $2.4 \mathrm{mEq} / \mathrm{l}$; urea $42 \mathrm{mg} \%$; other electrolytes normal; calcium, magnesium and liver function tests normal; random blood sugars 67 and $75 \mathrm{mg} \%$; faecal fat $6.7 \mathrm{~g} /$ day; Schilling test normal; stool culture negative; one VMA screening test was positive and one was negative, and a quantitative VMA excretion was normal; faecal potassium excretion was persistently raised between 45 and $68 \mathrm{mEq} / 24 \mathrm{hr}$ (normal 2-6 mEq/24 hr); urinary 24-hr potassium excretion was low between 10 and $20 \mathrm{mEq} / 24 \mathrm{hr}$ (normal 35-90 mEq/24 hr), see Fig. 1; a barium enema showed a dilated large bowel.

\section{Operation}

With a presumptive diagnosis of a pancreatic islet cell tumour laparotomy was performed. A well encapsulated tumour was found lying retroperitoneally above the body and tail of the pancreas and in front of and below the lower pole of the left kidney. This was removed with a small margin of surrounding tissue and immediate frozen section was reported as showing the appearances of a phaeochromocytoma. This was confirmed by paraffin sections, see Fig. 2 (histology). The only other abnormality noted at laparotomy was a very striking papery thinning of the large bowel. In particular a careful search of the pancreas revealed no abnormality. Extracts from the tumour revealed no gastrin activity. Histochemical studies for APUD cells were technically unsuccessful owing to unsuitable fixation.

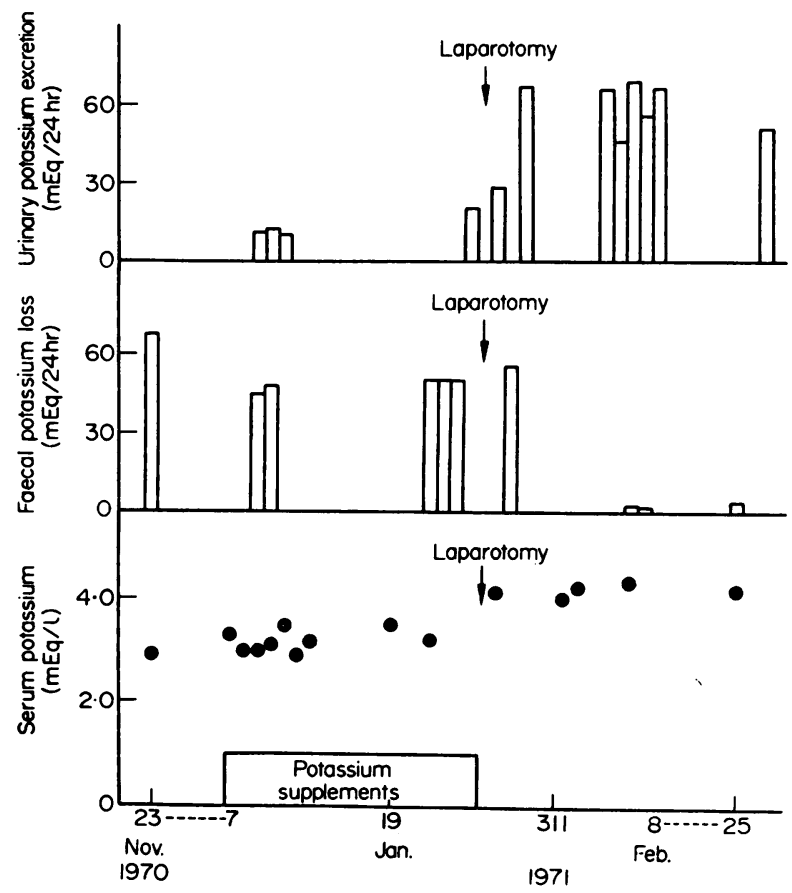

FIG. 1. Urinary and faecal potassium outputs, and serum potassium before and after operation. 


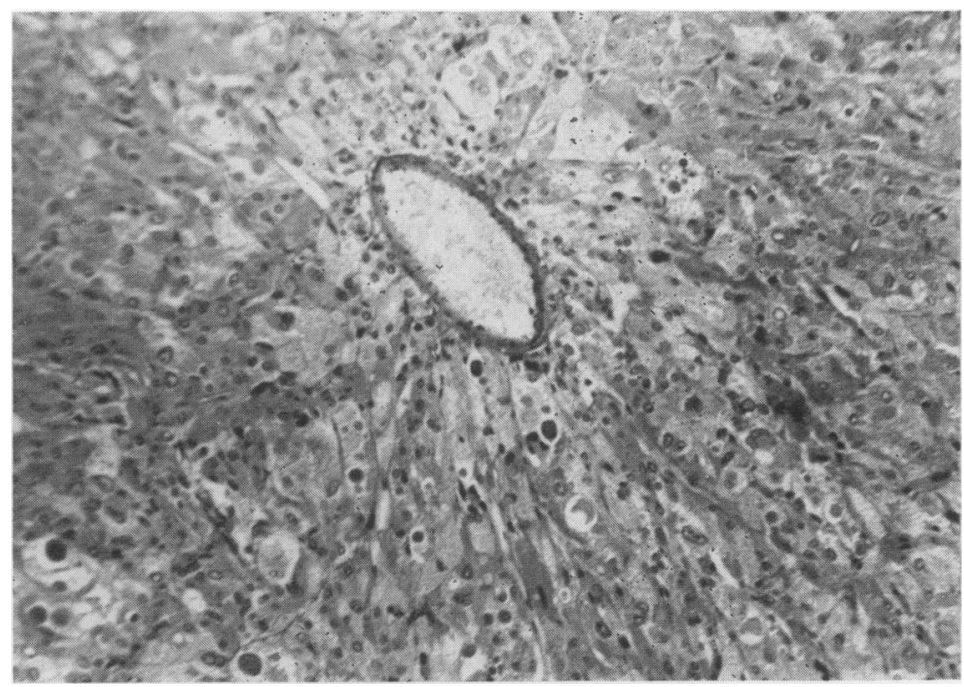

FIG. 2. Histological section of tumour.

\section{Progress}

After laparotomy she rapidly returned both symptomatically and biochemically to normal (see Fig. 1). She remained well until 6 months later, when she suffered an episode of left renal colic. An intravenous pyelogram confirmed three stones in the left ureter with a left hydronephrosis. Serum calcium, phosphate and uric acid were normal, as was the 24-hr urinary calcium excretion.A ureterolithotomy was performed and two stones were removed. During anaesthesia she developed a sinus tachycardia of 180 beats per minute and her systolic blood pressure rose to 180 $\mathrm{mmHg}$. Subsequent blood pressure recordings have been slightly elevated $(120 / 80-160 / 110 \mathrm{mmHg})$, but VMA excretion has been persistently normal.

At the time of writing, 3 years later, she remains well and has just been delivered of a normal baby.

\section{Discussion}

There is no recorded example of a WDHA syndrome occurring in association with a phaeochromocytoma. We propose that the tumour in this patient was producing both catecholamines and a hormone with VIP- or GIP-like activity. Other possible causes of the diarrhoea have been considered. Local bowel pathology was felt to be a very unlikely cause in the face of a normal rectal biopsy, normal small intestinal mucosal function and a rapid response to the removal of the tumour. The dilatation and thinning of the large bowel was thought to be a secondary phenomenon. Phaeochromocytomas, when they do affect bowel function, usually produce constipation (Jones et al., 1968; Melmon, 1968). Investigation excluded the production of excess gastrin, 5-hydroxy- indolacetic acid and thyroxine. Ectopic catecholamine production has been described producing diarrhoea, but in these cases the tumours were either ganglioneuromas or neuroblastomas. Hypercalcaemia is well described in the WDHA syndrome (Kraft, Tompkins and Zollinger, 1970), but although our case developed renal stones she at no time had a high serum calcium or a high urinary calcium excretion. Although symptomatically the patient has been cured by the removal of her tumour there still remains slight hypertension and one episode of tachycardia. It is theoretically possible that she has another similar tumour, or that her original tumour had produced functioning metastases. In view of this she requires ciose follow-up.

\section{Acknowledgements}

We would like to thank Mr J. E. Trapnell for permission to report this case, Dr D. Parish and Dr N. Padley for reporting and photographing the tumour, and Dr J. Polak for histochemical studies.

\section{References}

Bloom, S.R., Polak, Julia M. \& Pearce, A.G.E. (1973) Vasoactive intestinal peptide and watery diarrhoea syndrome. Lancet, ii, 14.

Brown, J.C. \& DRYBURGH, J.R. (1971) A gastric inhibitory polypeptide II; the complete amino acid sequence. Canadian Journal of Medicine, 49, 867.

DEMIS, D.J. (1963) The mastocytosis syndrome; clinical and biochemical studies. Annals of Internal Medicine, 59, 194.

Elias, E., Polak, J., Bloom, S.R., Pearce, A.G.E., Welbourne, R.B., Booth, C.C., Cuzio, M. \& Brown, J.C. (1972) Pancreatic cholera due to production of gastric inhibitory polypeptide. Lancet, ii, 791.

Gregory, 'R.A., Grosman, M.I., Tracey, H.J. \& Bentley, P.H. (1967) Nature of the gastric secretagogue in ZollingerEllison tumours. Lancet, ii, 543. 
Jones, N.F., WAlker, G., Ruthyen, C.R.J. \& SANdler, M. (1968) Alpha-methyl-p-thyrosine in the management of phaeochromocytoma. Lancet, ii, 1105.

Kraft, A.R., Tompkins, R.K. \& Zollinger, R.M. (1970) Recognition and management of the diarrheal syndrome caused by non-beta islet cell tumours of the pancreas. American Journal of Surgery, 119, 163.

Melmon, K.L. (1968) The endocrinologic manifestations of the carcinoid tumour. In: Textbook of Endocrinology (Ed. by R. H. Williams). W. B. Saunders, Co., Philadelphia, London, Toronto.

OAtes, J.A. \& Butler, T.C. (1967) Pharmacologic and endocrine aspects of carcinoid syndrome. Advances in Pharmacology, 5, 109.

Pedersen, R.A. \& Brown, J.C. (1972) Inhibition of histamine-pentagastrin and insulin-stimulated canine gastric secretion by pure 'gastric inhibitory polypeptide'. Gastroenterology, 62, 393.

Polak, J.M., Stagg, B. \& Pearce, A.G.E. (1972) Two types of Zollinger-Ellison syndrome immunofluorescent cytochemical and ultrastructural studies of the antral and pancreatic gastrin cells in different clinical states. Gut, 13, 501 .
Pearce, A.G.E. (1969) The cytochemistry and ultrastructure of polypeptide hormone-producing cells of the Apud Series and the embryologic, physiologic and pathologic implications of the concept. Journal of Histochemistry and Cytochemistry, 17, 303.

Rosenstein, B.J. \& Engelman, K. (1963) Diarrhea in a child with a catecholamine-secreting ganglioneuroma. Case report and review of the literature. Journal of Paediatrics. 63, 217.

SANDler, M., Karim, S.M.M. \& Williams, E.D. (1968) Prostaglandins in amine-peptide-secreting tumours. Lancet. ii, 1053.

Verner, J.V. \& Morrison, A.B. (1958) Islet cell tumor and a syndrome of refractory watery diarrhea and hypokalemia. American Journal of Medicine, 25, 374.

Williams, E.D., Karim, S.M.M. \& Sandler, M. (1968) Prostaglandin secretion by medullary carcinoma of the thyroid. Lancet, i, 22.

Zollinger, R.M. \& Ellison, E.H. (1955) Primary peptic ulcerations of jejunum associated with islet cell tumours of pancreas. Annals of Surgery, 142, 709.

Postgraduate Medical Journal (June 1975) 51, 419-422.

\title{
Skin metastases in carcinoma of the stomach
}

\author{
B. A. ADAM \\ M.B.B.S., M.R.C.P. \\ R. Murugasu \\ M.B.B.S. \\ Departments of Medicine and Pathology, Faculty of Medicine, University of Malaya, \\ Kuala Lumpur
}

\section{Summary}

A patient who presented with cutaneous nodules had carcinoma of the stomach. The histochemistry of the dermal infiltrate gave a clue to the primary site. Autopsy revealed metastases in all the organs of the chest and abdominal cavity. The invasion of the testis and the gingiva was unusual. Cutaneous metastases from a visceral malignancy probably indicate an early fatal termination.

Metastatic lesions to the skin from internal malignancies are rare and the incidence has been reported to vary from one to $2.7 \%$ (Gates, 1937; Beerman, 1957). Most reports quote lung and the breast as the primary site of malignancy although other sites including the stomach are not uncommon. The metastases, either single or multiple, may be the initial manifestations of the internal malignancy.

\section{Case report}

\section{History and physical examination}

Four months before admission to hospital, a 32year-old Indian male developed nodular eruptions initially on the forehead and the face (Fig. 1) and later on the upper part of the trunk. His appetite

Correspondence: Dr R. Murugasu, Department of Pathology, Medical Faculty, University of Malaya, Kuala Lumpur, Malaysia. became poor and he had lost some weight. There were no other symptoms. Clinical examination showed a well nourished individual. Nodules varying in size from 0.5 to $3 \mathrm{~cm}$ were found on the face, scalp, neck, chest wall, upper arms, and the back. They were attached to the skin and non-tender. The skin over the nodules was intact. In addition there were a few plaques of infiltrated skin with dilated follicular openings on the chin and the back of the neck. Oral, lingual and pharyngeal mucosa were intact but the gingiva showed gross hypertrophy without any evidence of infection (Fig. 2). There was no lymphadenopathy and the abdominal viscera were not palpable. Skin and gingival biopsies and a barium meal X-ray were done. On the fourth week of his stay in hospital, nodules appeared on the abdominal wall and enlarged lymph nodes were felt in the neck and the left axilla. Ascites soon appeared and the fluid was cloudy yellow. In the sixth week, he developed epigastric pain with three episodes of haematemesis and melaena. His right testis and the spermatic cord were found to be enlarged. $\mathrm{He}$ deteriorated and died at the end of the seventh week.

\section{Investigations}

Hb $14.0 \mathrm{~g} / 100 \mathrm{ml}$; WBC $3500 / \mathrm{mm}^{3}$; neutrophils $56 \%$; lymphocytes $37 \%$; eosinophils $7 \%$; ESR 13 